\title{
Progression dans un paysage enneigé
}

\section{Claude Simon}

\section{(2) OpenEdition}

Journals

Édition électronique

URL : http://journals.openedition.org/ccs/564

DOI : $10.4000 /$ ccs.564

ISSN : 2558-782X

\section{Éditeur :}

Presses universitaires de Rennes, Association des lecteurs de Claude Simon

\section{Édition imprimée}

Date de publication : 30 avril 2007

Pagination : 13-17

ISBN : 9782354120122

ISSN : 1774-9425

\section{Référence électronique}

Claude Simon, «Progression dans un paysage enneigé », Cahiers Claude Simon [En ligne], 3 | 2007, mis en ligne le 20 septembre 2017, consulté le 15 septembre 2020. URL : http://journals.openedition.org/ $\operatorname{ccs} / 564$ 


\section{PROGRESSION DANS UN PAYSAGE ENNEIGÉ}

\section{Claude Simon}

Il s'enfonce au petit trot dans le bois. Sans presque qu'il ait à la guider sa monture se faufile entre les troncs noirs des arbres. De temps en temps il est obligé de se pencher sur l'encolure pour éviter une branche basse. Deux petits nuages de vapeur fusent des naseaux de la jument. Ses sabots s'enfoncent en silence dans la neige. Les seuls bruits que l'on entende sont ceux du souffle de l'animal, parfois coupé par une expiration plus violente comme un éternuement, un tintement d'acier (le mors et le filet mâchonnés, le fourreau du sabre contre l'étrier) ou le craquement assourdi d'une branche morte que la jument écrase au passage. Parfois le déplacement de l'air, ou peutêtre les imperceptibles vibrations du sol frappé par les sabots, font se détacher d'une branche un paquet de neige qui glisse lui aussi sans bruit. Il perçoit seulement un choc léger sur son chapeau ou une épaule, comme celui d'une main qui se poserait doucement. À la cadence du trot les paillettes brillantes glissent par saccades, poudrant le rabat d'une sacoche, le drap de sa culotte au genou. Elles ne fondent même pas au contact de l'étoffe et s'éparpillent peu à peu. Toutefois quelques fines traînées restent accumulées le long des coutures, dans les fronces du cuir et les plis du vaste manteau dont il a rejeté un pan par-dessus son épaule. Le ciel est gris, bas, d'une couleur de fer. Quand au sortir du taillis il met la jument au galop, le souffle de celle-ci se fait plus rapide. À chaque foulée l'air chassé par les poumons fait claquer rapidement l'une contre l'autre les lèvres molles. 


\section{II}

C'est tout juste s'il a besoin de déplacer légèrement sa main pour infléchir la course de la jument qui se dirige au petit trot vers la lisière du bois, se faufilant entre les troncs des arbres. Sur la blancheur de la neige les troncs semblent d'un noir uniforme. De près l'écorce des bouleaux apparaît pourtant d'un gris argenté, rosé par endroits, parsemée de fentes horizontales et charbonneuses, comme les lèvres de blessures. Les pins ont d'épaisses écailles d'un brun rougeâtre. Les sommets des écailles retiennent de minuscules entablements de neige accumulée. Deux fuseaux de vapeur bleuâtre s'échappent régulièrement des naseaux du cheval. Chassés d'abord vers le bas, ils s'élèvent lentement dans l'air glacé où ils se dissolvent. Malgré la protection du gant un étau douloureux écrase l'extrémité des doigts de la main qui tient les rênes. Autour de lui les troncs verticaux passent les uns derrière les autres comme les barreaux de grilles animées d'un lent mouvement horizontal, à des vitesses qui varient selon la distance. Les sabots s'enfoncent sans bruit dans la neige où ils laissent l'empreinte des fers. Parfois la neige accumulée force la jument à ralentir et elle n'avance plus qu'au pas, levant haut ses jambes de devant, comme si elle piaffait, dégageant son arrièretrain par de petites croupades et laissant derrière elle dans la neige un profond sillon coupé d'éboulis. Son souffle alors s'accélère. Dans les bottes durcies par le gel, les pieds semblent faire bloc avec le cuir. Le ciel bas a une couleur métallique, légèrement cuivrée. La jument donne de musculeux coups de reins pour se dégager des congères. Il l'aide à prendre appui sur le mors en élevant la main qui tient les rênes et serre les cuisses pour se maintenir en selle. Secoués par les efforts vigoureux de l'animal, le fourreau du sabre et un étrier s'entrechoquent avec un tintement clair dans le silence qui l'absorbe aussitôt. Aucun vent n'agite la cime des arbres. Parfois, sans raison apparente, sans que rien n'ait bougé dans les taillis, sans qu'il ait vu s'envoler un oiseau, des paquets de neige se détachent, glissent de rameau en rameau, entraînant d'autres paquets en une petite avalanche qui se pulvérise sur une branche basse, et la vitesse plaque sur son visage une poudre de paillettes scintillantes qui ne fondent même pas à la chaleur de la peau, restent attachées aux 
barbes du drap et s'accumulent peu à peu, au rythme du trot, dans les plis drapés de son manteau. Il tient toujours haut les rênes, prêt à relever la tête du cheval s'il butait contre un obstacle, une des branches mortes, invisibles sous la neige, et que l'on entend parfois craquer avec un bruit assourdi.

\section{III}

Le froid enserre ses pieds dans des bottes de fer. Il peut le sentir gagner lentement de proche en proche et remonter le long de ses jambes. De petits amas de neige retenus par de faibles aspérités font paraître plus sombres les troncs argentés des bouleaux dont l'écorce, d'un rose délicat par endroits, se crevasse d'entailles horizontales, comme des bouches noires aux lèvres éclatées. Il y a aussi de la neige gelée sur les fûts écailleux des pins, d'un gris mauve, dont les saillies offrent des rugosités où elle s'accroche, recouvrant parfois complètement d'un côté sous sa couche grumeleuse les troncs entre lesquels se faufile le cheval au petit trot à peine guidé par les infimes déplacements de la main. Bientôt une légère vapeur s'élève autour du poitrail et des épaules du cheval qui parfois ralentit, prend le pas et peine pour se dégager d'une congère, arrachant ses jambes l'une après l'autre, balançant son encolure et s'aidant de coups de reins nerveux, en proie à un léger affolement que le cavalier calme de la voix, obligé toutefois de serrer les genoux et de se pencher en arrière pour amortir les soubresauts du grand corps musculeux. Le ciel est sombre, décoloré, les masses étirées des nuages immobilisées en une succession de bandes faiblement boursouflées formant un plafond continu, sans une fissure, modelées ton sur ton à la mine de plomb dans un dégradé de gris métalliques, presque noirs devant lequel s'entrecroisent les extrémités fourchues des branches. Il lui semble qu'un clou de glace est enfoncé sous chacun des ongles de la main qu'il élève maintenant à hauteur de sa poitrine, tendant les rênes pour permettre au cheval de prendre appui sur le mors, l'aider à se dégager des congères et l'empêcher de trébucher s'il s'embarrassait les jambes dans une branche morte invisible sous la neige. Le silence semble absorber aussitôt tous les bruits. Comme si la calotte striée des nuages bas, étroitement soudée à l'horizon de 
la plaine enneigée, enfermait la forêt, le paysage tout entier, sous un couvercle d'acier qu'aucun son ne parvient à traverser. On n'entend pas un seul oiseau dans le bois. Même pas le froissement furtif d'une petite bête surprise, s'enfuyant dans les fourrés. Pas un chant, pas un appel. Pourtant, tout à l'heure, alors que le cheval peinait, enfoncé jusqu'au poitrail, il a pu voir les empreintes délicates laissées sur la neige par des pattes en forme de trident : un chapelet de minuscules éventails dessinant des arabesques paresseuses, sans but apparent, revenant parfois sur elles-mêmes, se recoupant, traçant des boucles. Par endroits les effets du vent, les tourbillons entre les arbres, ont modelé la neige en forme de vagues et sous les épaisses crêtes d'écume solidifiée on peut voir les herbes courbées par leur poids, solidifiées aussi, gelées et jaunies, nécrosées. Ses pieds lui semblent pris dans des étriers de froid. Dès qu'il s'est dégagé de la congère il remet le cheval au trot. Toutefois le mouvement n'amène aucun réchauffement. Souvent il est obligé d'incliner son buste en avant ou sur le côté pour éviter d'être griffé par une branche basse ou passer au-dessous, ou encore il sort sa main gauche de sous son manteau pour écarter un rameau. Parfois aussi il sent soudain sur son chapeau ou sur son épaule un poids léger qu'aucun bruit n'a annoncé, et le paquet de neige glisse en se brisant dans les plis du manteau. D'autres fois c'est comme un brouillard de paillettes impalpables qu'il reçoit sur le visage. Elles pénètrent dans son nez, ses yeux et sa bouche où elles fondent rapidement. Elles ont une saveur métallique, comme des particules de fer, de la limaille, pas désagréable. Celles qui restent accrochées à ses sourcils ne fondent pas et en levant les yeux il peut voir une frange blanchâtre et floue. Malgré le pan du manteau qu'il a rejeté sur une épaule et dans lequel s'engonce son menton quelques cristaux s'infiltrent sous sa cravate dans le col de sa chemise. Le fourreau de son sabre tinte à chaque foulée du cheval contre l'étrier droit et avec le souffle de la bête c'est le seul bruit que l'on entende, insolite, énorme, dans la chape de silence. Il arrive aussi que lorsqu'ils passent sous une branche lourdement chargée, les trépidations pourtant imperceptibles du sol, ou encore le déplacement de l'air, déclenchent la chute d'un gros paquet de neige qui tombe avec un faible chuintement, comme une cascade, un rideau blanc, juste après leur passage, s'affalant sur le 
sol avec un bruit mou, poudrant quelquefois la croupe du cheval sur laquelle les cristaux scintillent un instant avant de s'éteindre. De la vapeur s'élève du pelage mouillé. La robe acajou du cheval est teintée de sombre par la neige fondue et la sueur : de petites taches d'abord, ocellée, puis des pans entiers, presque noirs. Le cou aussi commence à s'humecter de sombre sur les côtés. Se détachant sur le blanc absolu de la neige, les parties où le poil est encore sec semblent presque rouges. De petits glaçons restent pris dans la crinière noire. Au sortir des derniers taillis, dans la plaine, la neige balayée par le vent est moins épaisse et l'on peut même voir les extrémités des chaumes qui crèvent la croûte gelée. Pendant quelques instants il continue au trot et il peut maintenant entendre la mince couche de glace qui craque sous les sabots. À la fin il serre un peu les jambes et met le cheval au galop. 